\title{
Correction: Phosphorescence Monitoring of Hypoxic Microenvironment in Solid-Tumors to Evaluate Chemotherapeutic Effects Using the Hypoxia-Sensitive Iridium (III) Coordination Compound
}

\author{
The PLOS ONE Staff
}

There are errors in the Funding section. The correct funding information is as follows:

"Funding was provided by the National Natural Science Foundation of China, No. $81471771,81271686,81000628,31000379$. The funders had no role in study design, data collection and analysis, decision to publish, or preparation of the manuscript."

\section{Reference}

1. Zeng Y, Liu Y, Shang J, Ma J, Wang R, Deng L, et al. (2015) Phosphorescence Monitoring of Hypoxic Microenvironment in Solid-Tumors to Evaluate Chemotherapeutic Effects Using the Hypoxia-Sensitive Iridium (III) Coordination Compound. PLoS ONE 10(3): e0121293. doi:10.1371/journal.pone.0121293 PMID: 25786221

\section{f open access}

Citation: The PLOS ONE Staff (2015) Correction: Phosphorescence Monitoring of Hypoxic Microenvironment in Solid-Tumors to Evaluate Chemotherapeutic Effects Using the HypoxiaSensitive Iridium (III) Coordination Compound. PLoS ONE 10(4): e0126302. doi:10.1371/journal. pone. 0126302

Published: April 13, 2015

Copyright: $\odot 2015$ The PLOS ONE Staff. This is an open access article distributed under the terms of the Creative Commons Attribution License, which permits unrestricted use, distribution, and reproduction in any medium, provided the original author and source are credited. 